\title{
Identification and use of the sugarcane bacilliform virus enhancer in transgenic maize
}

\author{
John P Davies ${ }^{1 *}$, Vaka Reddy ${ }^{1,3}$, Xing L Liu', Avutu S Reddy ${ }^{2}$, William Michael Ainley², Mark Thompson², \\ Lakshmi Sastry-Dent ${ }^{2}$, Zehui Cao ${ }^{2}$, James Connell ${ }^{2}$, Delkin O Gonzalez ${ }^{2}$ and Douglas Ry Wagner ${ }^{1,2,4}$
}

\begin{abstract}
Background: Transcriptional enhancers are able to increase transcription from heterologous promoters when placed upstream, downstream and in either orientation, relative to the promoter. Transcriptional enhancers have been used to enhance expression of specific promoters in transgenic plants and in activation tagging studies to help elucidate gene function.

Results: A transcriptional enhancer from the Sugarcane Bacilliform Virus - Ireng Maleng isolate (SCBV-IM) that can cause increased transcription when integrated into the the genome near maize genes has been identified. In transgenic maize, the SCBV-IM promoter was shown to be comparable in strength to the maize ubiquitin 1 promoter in young leaf and root tissues. The promoter was dissected to identify sequences that confer high activity in transient assays. Enhancer sequences were identified and shown to increase the activity of a heterologous truncated promoter. These enhancer sequences were shown to be more active when arrayed in 4 copy arrays than in 1 or 2 copy arrays. When the enhancer array was transformed into maize plants it caused an increase in accumulation of transcripts of genes near the site of integration in the genome.
\end{abstract}

Conclusions: The SCBV-IM enhancer can activate transcription upstream or downstream of genes and in either orientation. It may be a useful tool to activate enhance from specific promoters or in activation tagging.

Keywords: Promoter, Enhancer, Transcription, Transgenic plant, Transient assay

\section{Background}

Enhancers are DNA elements that are able to increase transcription from other promoters whether they are placed upstream or downstream of transcription start sites and their promoter enhancing activity is independent of orientation relative to the transcription start site $[1,2]$. Enhancers that are effective in plants have been isolated from genes of plants as well as from genes of viruses and bacteria that infect plants. These include enhancers from the tobacco tCUP $[3,4]$, the pea plastocyanin [5], the Cauliflower mosaic virus 35S (CaMV 35S) [6,7], the Figwort mosaic virus [8] and the Agrobacterium tumefacians $780[9,10]$ and ocs promoters [11].

Plant virus-derived promoters have been shown to be a rich source of strong constitutive promoters for use in plant biology and several have been shown to contain

\footnotetext{
* Correspondence: jdavies3@dow.com

'Dow AgroSciences, 16160 SW Upper Boones Ferry Rd, Portland, OR 97224, USA

Full list of author information is available at the end of the article
}

enhancer sequences $[6,8]$. The CaMV $35 \mathrm{~S}$ promoter has been used extensively in driving transgenes in transgenic plants. Many other viral promoters have also been shown to effectively drive expression of transgenes; CaMV 19S, Rice tungro bacilform virus (RTBV) [12], Soybean chlorotic mottle virus [13], Mirabilis mosaic virus [14,15], Figwort mosaic virus (FMV) [16,17], Peanut streak chlorotic virus [18], Banana streak badnavirus [19], Cestrum yellow leaf curling virus (CmYLCV) [20] and Sugarcane bacilliform badnavirus (SCBV) [19,21,22]. Among these, the CaMV 35S and the FMV promoters have been demonstrated to have enhancer sequences within the promoter $[6,8]$.

The CaMV 35S enhancer [7] is the most common enhancer used in plant biology. Several studies have shown that the CaMV $35 \mathrm{~S}$ promoter is not as active as other strong constitutive promoters in monocots [23-26], raising the question whether the CaMV 35S enhancer sequences are as effective in monocots as they are in dicots. However, $2 \mathrm{x}$ and $4 \mathrm{x}$ arrays of the 
CaMV 35S enhancer have been shown to enhance transcription of heterologous promoters in stable transformants of rice as well as to cause increased transcript accumulation of endogenous genes [27-30].

The Sugarcane bacilliform virus (SCBV), like the Cauliflower mosaic virus, is in the Caulimoviridae family of viruses. While the Cauliflower mosaic virus is in the Caulimovirus genus and mostly infects dicots, SCBV is in the Badnavirus genus along with Commelina yellow mottle virus (CoMV) and RTBV and infects monocots [21]. Badnaviruses have circular genomes that produce a terminally redundant transcript [31,32]. Like CoMV, SCBV has three large open reading frames on its plus strand [33]. Promoters from several Badnaviruses have been shown to drive expression of heterologous genes in transgenic plants $[16,19,22,34,35]$. Because these viruses infect monocots, they may be useful sources of strong promoters for monocots. SCBV promoters from several isolates of the virus have been tested in transgenic plants and shown to be highly expressed in most tissues tested [21,22,36].

We present a characterization of an $839 \mathrm{bp}$ fragment of the Sugarcane Bacilliform Virus - Ireng Maleng isolate (SCBV-IM) promoter and demonstrate that it is comparable in strength to the strong maize ubiquitin 1 (ZmUBI1) promoter in transgenic maize. This work also presents a dissection of the SCBV-IM promoter and the identification of sequences that can enhance transcription when placed upstream of a truncated maize alcohol dehydrogenase (ZmADH1) promoter. Similar to what was seen with the CaMV 35S enhancer [8,37-39], multiple tandem copies of the SCBV-IM enhancer are more effective in increasing transcription than a single copy. An activation tagging element containing four tandem copies of the enhancer element has been introduced into maize. Examination of events containing the activation tagging element indicates that the $4 \mathrm{x}$ SCBV-IM enhancer is capable of causing an increase in accumulation of transcripts of native maize genes near the site of insertion of the SCBV-IM enhancer.

\section{Results}

The SCBV-IM promoter is a strong promoter in transgenic maize

To compare the strength of the SCBV-IM promoter relative to a known strong promoter, transgenic plants containing SCBV-IM::AAD1 and ZmUBI1::AAD1 transgenes were generated. AAD1 encodes an enzyme that degrades 2,4-D and aryloxyphenoxypropionate herbicides and plants expressing this gene are tolerant of these herbicides [40]. Transcript accumulation was measured in samples from various tissues of T1 plants by RT-qPCR. Tissue samples were taken from the youngest fully expanded leaf at the V3, and V8 stages, from the leaf below the developing ear at the R1 stage, from a $1 \mathrm{~cm}$ section from the tip of a root at V3 and V10 stages and from the tassels at R1 stage. Figure 1 shows AAD1 transcript accumulation in 3 events containing each transgene. In the leaf samples collected at V3 stage, plants containing the SCBV-IM::AAD1 transgene accumulate more transcript than plants containing ZmUBI1::AAD1 (Figure 1A), at the V8 stage, leaves accumulate similar amounts of AAD1 transcripts (Figure 1B) while in the leaf samples of R1 plants lower levels of AAD1 transcript accumulate in the SCBV-IM:: AAD1 transgenic plants (Figure 1C). In the roots of V3 and V10 plants, SCBV-IM::AAD1 transgenic plants accumulate more of the AAD1 transcripts than ZmUBI1:: AAD1 transgenic plants (Figure 1D and E). In tassel tissues, ZmUBI1::AAD1 transgenic plants accumulate more AAD1 transcript. These results demonstrate that the SCBV-IM promoter is stronger or comprable in strength to the strong, constitutively expressed maize ubiquitin 1 promoter [26] in young leaf and root tissues, but is weaker in the leaf below the devloping ear and in tassel tissues at R1.

\section{SCBV-IM enhancer identification and characterization}

The activity of the SCBV-IM enhancer was demonstrated in transient assays first by identifying sequences that are necessary for high levels of transcription and then by identifying sequences that can enhance transcription from a heterologous promoter. The sequence of the SCBV-IM promoter is shown in Figure 2; the transcription start site was mapped by $5^{\prime}$ RACE.

SCBV-IM promoter fragments SCBV839, SCBV576 and SCBV333 (Figure 2) were cloned upstream of the luciferase (LUC) reporter gene. Transcriptional activities of these constructs were tested by transfecting maize $\mathrm{Hi}-\mathrm{II}$ suspension cells and monitoring relative activities of the reporter genes.

To test the activities of different SCBV-IM promoter fragments, equal molar concentrations of the test plasmids and a reference plasmid (ZmUBI:GUS), used as an internal control to normalize for differences in transformation efficiency, were co-introduced into maize Hi-II suspension cell cultures by particle bombardment. Two days after the bombardment, total protein was isolated from transfected cells and LUC and GUS enzymatic activities were determined. Activity was expressed as the ratio of LUC to GUS activity. The results show that the promoter fragment SCBV576 had $60 \%$ of the activity of the SCBV839 promoter fragment (Figure 3) and the SCBV333 promoter fragment had only $10 \%$ of the activity of the SCBV839 fragment. These data indicate that sequences necessary for most of the SCBV-IM promoter activity reside upstream of the 333 bp fragment.

Next, two upstream fragments of the SCBV-IM promoter were tested for their ability to enhance transcription from a truncated heterologous promoter. Two fragments of the SCBV-IM promoter (SCBV282 consisting 

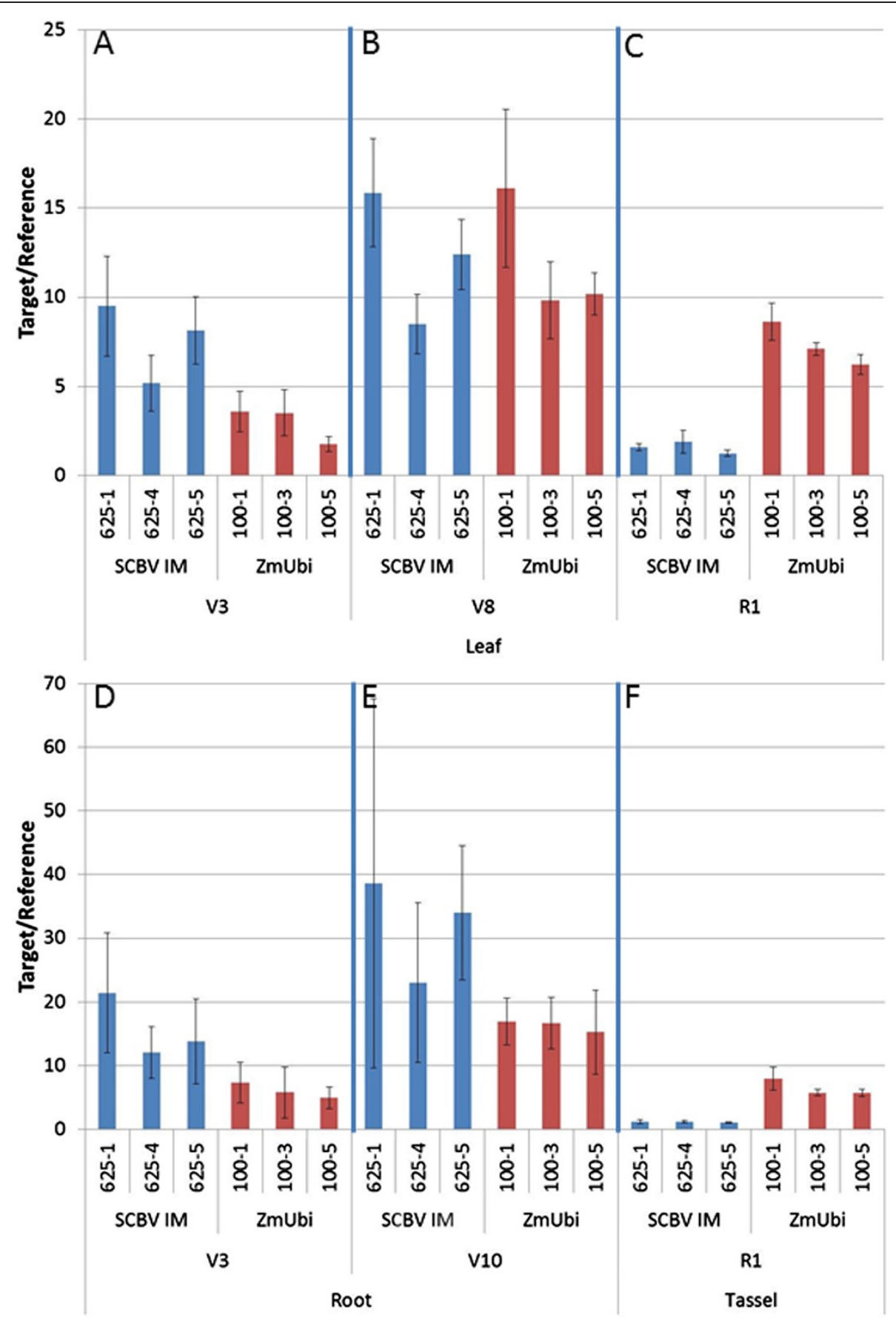

Figure 1 Comparison of the SCBV-IM and ZmUBI1 promoters in transgenic maize tissues. Transgenic, single copy maize events containing SCBV-IM::AAD1 and ZmUBI1::AAD1 constructs were analyzed for AAD1 transcript accumulation in the youngest fully expanded leaf of V3 (A) and V8 (B) stage plants, the leaf just below the ear of R1 plants (C), a $1 \mathrm{~cm}$ section from the tip of the root in V3 (D) and V10 (E) stage plants, and in the tassels of R1 stage plants (F). Three events for each of the two constructs were compared by RT-qPCR using primers specific to the AAD1 transcript and normalized to an endogenous transcript, TIP (for leaf and tassel tissues) or MAZ95 (for root tissues). The error bars represent the standard deviation of three measurements. Analysis of Variance $(\alpha=0.05)$ indicate that more AAD1 transcript accumulate in the SCBV-IM::AAD1 events than in ZmUBI1 ::AAD1 events in leaves of V3 stage plants, the roots of V3 and V8 stage plants, while similar levels of AAD1 transcript accumulate in leaves of V8 stage plants. ZmUB11::AAD1 transgenic plants accumulate more AAD1 transcript than SCBV-IM::AAD1 transgenic plants in leaf and tassel tissues at R1.

of sequences -434 bp to $-153 \mathrm{bp}$ and SCBV537 consisting of sequences from -689 to -153 , relative to the transcription start site) were cloned upstream of a truncated maize alcohol dehydrogenase 1 (ZmADH1) promoter $(-100$ to +106 , relative to the transcription start site) [41] fused to the firefly luciferase gene. These constructs 
A

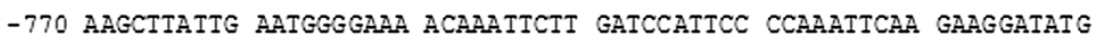

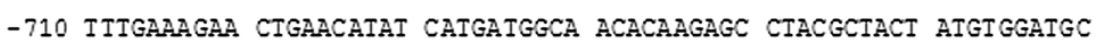

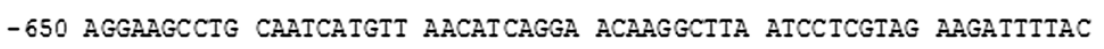

-590 AAGIGIGCCA IGAATATCTG CCACTGCTGG TAITGGGCAG AITTACTTGA AGAATACGIG

-530 CAAGAGAGGA TCGAAGATTI CATGGTTGAA AACTTCGACA AGAAAGCAAA GCTGGATGAA

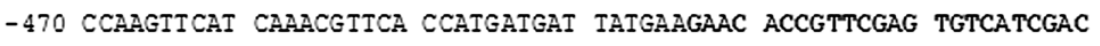

- 410 AGGCCAAGGC CAACAGATGA TCATTTCAGA CCATGGGGG ATGTTACATA CTGGCTGAAT

-350 AAAGAAGCAG AAGAGTGCCA CACAAGGGGC GACAACGTCG AAGGCGCAGA AGACGCAGTC

-290 GATCTCACTG ACGTAAGCAA TGACGACCAG TGGAGGAGAT CGTAAGCAAT GACGTATGGA

-230 GCGTGGAGGA CCCATGAAAG CACTGAGAAG GCATCTCAAC TTTCGGTGTG TGAGTGCGCA

-170 TCCTATGCGA TGCTTTGIAC CITTGITAGC IGIGIGIGIC CITITGGCAT CIGIGCCACT

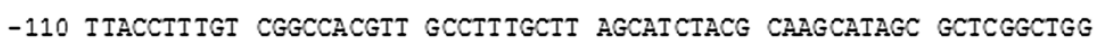

-50 IGIGIGITCC CTCTGCCTAT ATAAGGCATG GITGTATGAC ICTTACACTC AICGGIAGIT

11 CACCACATGA GTATTTGAGI CAAGI ITGGC ITGAATAATA AGAAITACAC CTITCCGCA

B

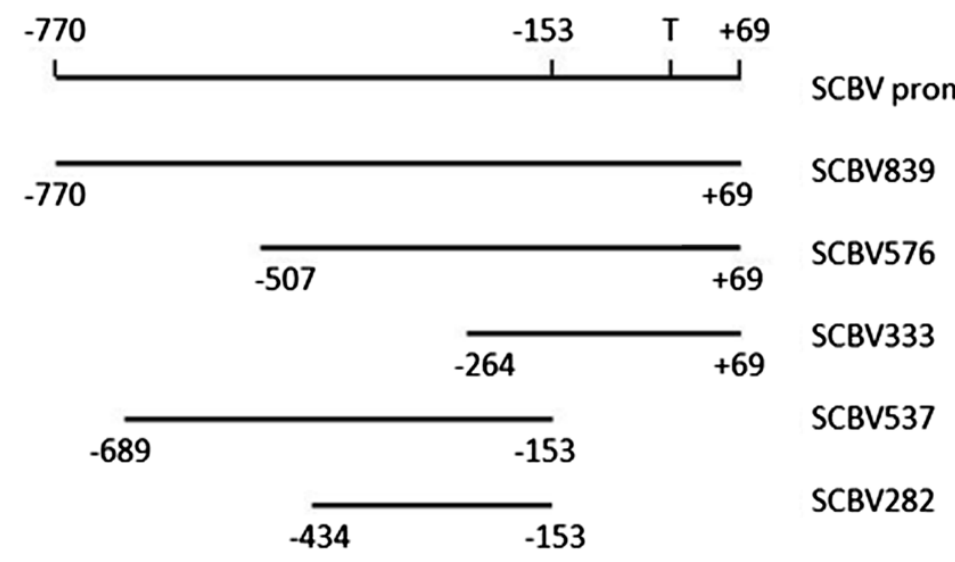

Figure 2 SCBV promoter sequence (A) and fragments used in experiments (B). (A) The transcription start site was mapped by $5^{\prime}$ RACE and sequences in the $5^{\prime}$ untranslated region of the transcript are underlined (position $1-69$ ). The putative TATA box is underlined at position $-28--33$. The SCBV-IM enhancer sequences are in bold. (B) The fragments of the SCBV-IM promoter used in transient assays are displayed. The position of the transcription start site $(\mathrm{T})$ is shown.

were designated SCBV282::ZmADH1::LUC and SCBV537:: ZmADH1::LUC, respectively.

Maize Hi-II suspension cells were transfected with plasmids SCBV282::ZmADH1::LUC, SCBV537::ZmADH1::LUC and ZmADH1::LUC (with no SCBV-IM sequences) along with the reference plasmid containing ZmUBI1::GUS. Overall, these promoters gave much lower activity than the intact SCBV promoter (Figure 4). This may be because the $\mathrm{ZmADH} 1$ chimeric promoters are inherently weaker than the intact SCBV-IM promoter or because a promoter fragment of the SCBV-IM promoter necessary for high activity was not included in the chimeric constructs.

The results shown in Figure 4 indicate that the SCBV282 fragment (containing sequence from $-434 \mathrm{bp}$ to $-153 \mathrm{bp}$ ) was able to enhance activity of the truncated ZmADH1 promoter more effectively than the larger SCBV537 fragment (containing sequences from $-689 \mathrm{bp}$ to $-153 \mathrm{bp}$ ). These results indicate that these fragments of the SCBV-IM promoter cause an increase in activity of the reporter gene driven by a truncated heterologous 

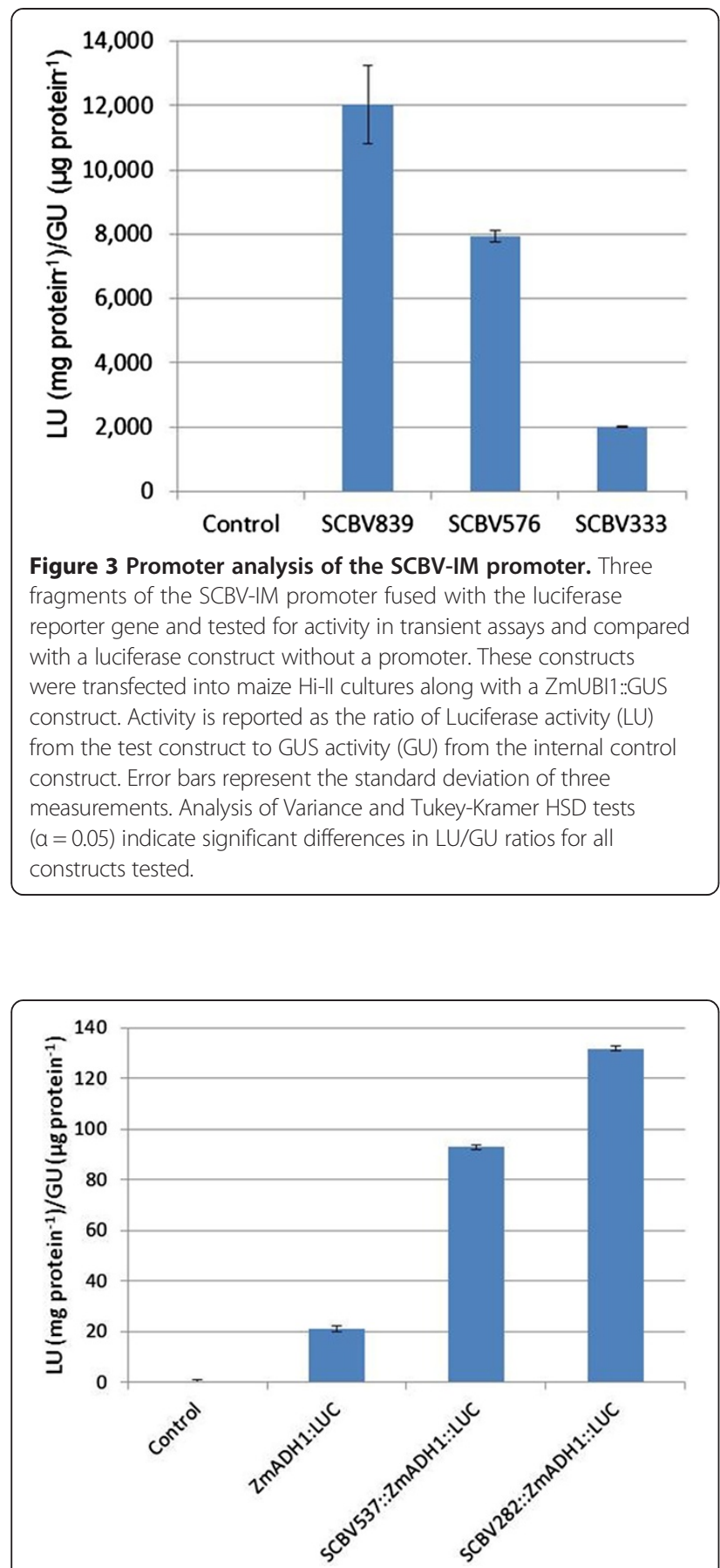

Figure 4 Enhancer analysis of the SCBV-IM promoter. Two fragments of the SCBV-IM promoter were fused with the truncated $\mathrm{ZmADH} 1$ promoter and the luciferase reporter gene. These constructs were tested for activity in transient assays and compared with a construct containing only the minimal $\mathrm{ZmADH} 1$ promoter. These constructs were transfected into maize Hi-ll cultures with a ZmUBI1::GUS construct. Activity is reported as the ratio of luciferase activity (LU) from the test construct to GUS activity (GU) from the internal control construct. Error bars represent the standard deviation of three measurements. Analysis of Variance and Tukey-Kramer HSD tests $(a=0.05)$ indicate significant differences in LU/GU ratios for all constructs tested. promoter, and that most of this enhancing activity lies within the $-434 \mathrm{bp}$ to $-153 \mathrm{bp}$ region.

To determine whether multiple copies of the SCBV-IM enhancer are more effective in activating transcription, 1 , 2 and 4 copies of the SCBV282 fragment were cloned upstream of the truncated $\mathrm{ZmADH} 1$ promoter fused to the LUC gene and bombarded into maize Hi-II suspension cells. Constructs containing 1, 2 and 4 tandem copies of the SCBV-IM enhancer had 5 times, 6 times and 10 times more activity, respectively, than did cells bombarded with the ZmADH1::LUC construct without any SCBV-IM sequences (Figure 5). It should be noted that in the experiment shown in Figure 5, the activity of SCBV282:: ZmADH1::LUC and ZmADH1::LUC was substantially greater than in the experiment shown in Figure 4. However, similar variation in promoter activity between independent experiments conducted with different cell preparations has previously been reported [42].

\section{SCBV-enhancer activity in stable maize transformants}

To determine whether the SCBV-IM enhancer can increase expression of genes within the maize genome, an activation tagging construct consisting of the $4 \mathrm{x}$ tandem array of the

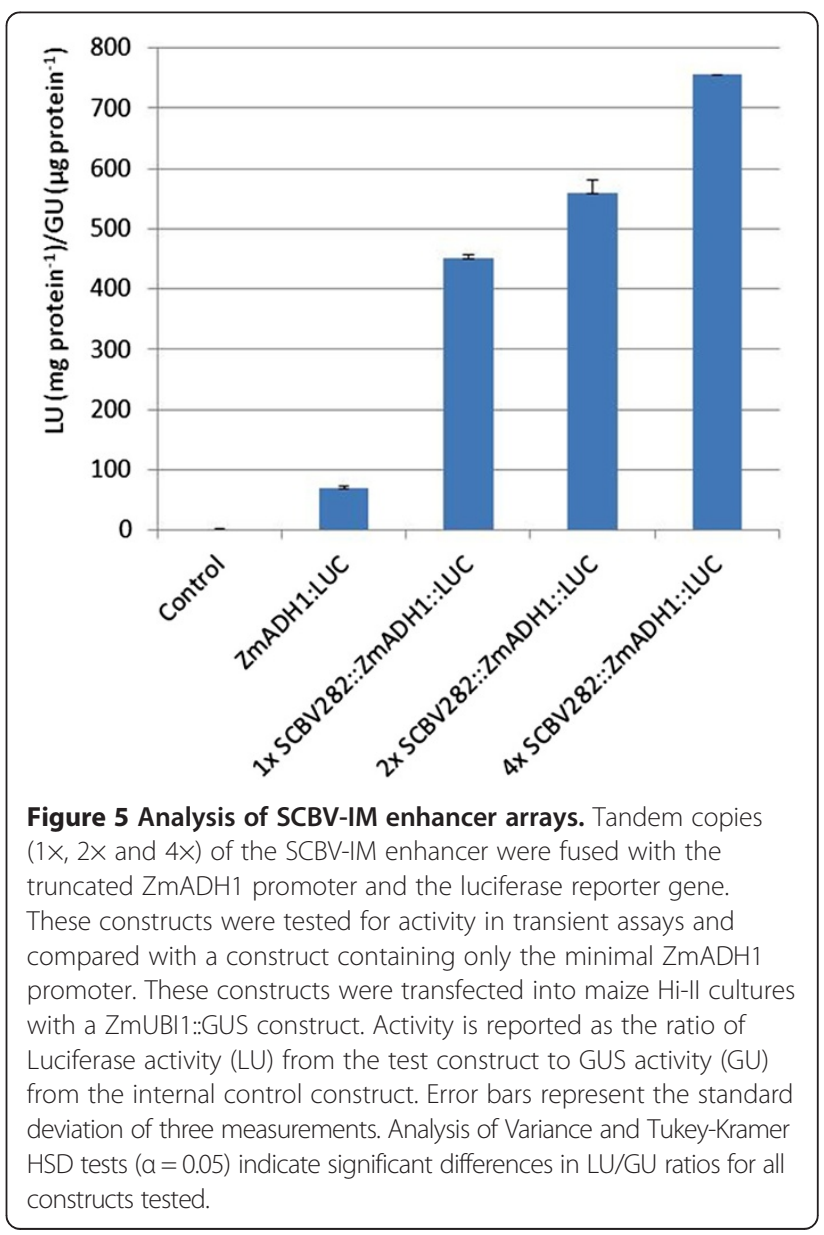


SCBV282 enhancer (Figure 6) and a selectable marker composed of the rice actin promoter driving expression of the AAD1 herbicide resistance gene and the maize lipase 3' UTR [43] was cloned and transformed into maize plants via Agrobacterium-mediated transformation.

Transformants were examined for the location of the T-DNA insertion and the proximity of the enhancers to annotated genes in the maize genome that were reported to be expressed at moderate levels in leaf tissues [44]. Determination of the site of integration of the construct was attempted for 223 events by a transgene border sequence identification method [45] and 107 of these events were mapped to locations in the maize B73 reference genome. To determine whether the enhancers within the T-DNA sequence are able to cause an increase in transcript accumulation of endogenous genes, these transformants were examined to identify T-DNA insertion sites within $\sim 5.5 \mathrm{~Kb}$ of a gene. The CaMV 35S enhancer has been demonstrated to up-regulate genes within $\sim 8 \mathrm{~Kb}$ of the enhancer sequences $[29,46]$.

Eleven events were examined to determine whether transcripts of genes adjacent to the activation tagging element were more abundant in the transgenic events than non-transgenic control plants. For five of these genes (GRMZM2G078472, GRMZM2G142119, GRM ZM2G071986, GRMZM2G444075 and AC183888.4_ FG008), no transcripts were detected in either the transgenic or non-transgenic lines. For the six other genes, transcripts were detected from genes adjacent to the activation tagging element. In these events, two genes (GRMZM2G456132 and GRMZM2G065718) showed a similar level of these transcripts in transgenic and non-transgenic plants (Figure 7). However, in 4 other events the transcripts of genes adjacent to the activation tagging element were more abundant in the transgenic plant than the non-transgenic plant. For two genes (GRMZM2G140537 and GRMZM2G104760), the transgenic plant showed more transcript than did the nontransgenic plant; this increase in abundance was 2.5 and 3.2 fold, respectively. For the other two genes (GRMZM2G010372 and GRMZM2G054713), no transcript was detectable in the non-transgenic plant but transcript

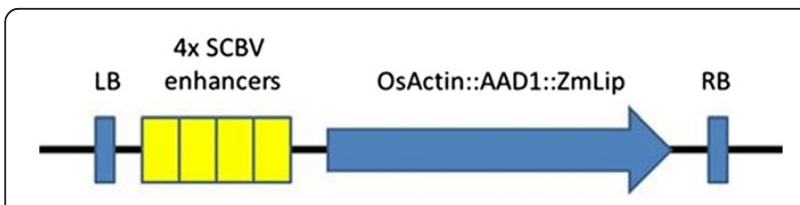

Figure 6 Schematic of enhancer construct, pEPS1027, used in maize transformation. The construct includes an array of 4 copies of the SCBV-IM enhancers (yellow boxes) and the AAD1 herbicide resistance gene (blue arrow) containing the rice actin promoter

fused with the AAD1 gene and the maize lipase $3^{\prime}$ UTR relative to the left border (LB) and right border (RB) of Agrobacterium T-DNA. was clearly detectable in the transgenic plant. These results demonstrate the $4 \mathrm{x}$ tandem array of the SCBV-IM enhancer can increase transcript abundance in a stable transformed maize plant and in some cases may cause ectopic expression of genes that are not expressed, or expressed at very low levels. It also indicates that the $4 \mathrm{x}$ tandem array of the SCBV-IM enhancer meets the traditional definition of an enhancer $[47,48]$ because it can function upstream or downstream of the transcription unit and in either orientation.

\section{Discussion}

The promoter sequences that we define include significant portions of the SCBV ORF III gene. The SCBV839 sequence, which has the greatest activity in transient assays, overlaps with 525 protein coding nucleotides. The sequences overlapping the ORF III gene contain most of the promoter activity as demonstrated by the SCBV333 fragment containing only $20 \mathrm{bp}$ of the ORF III gene and having just $10 \%$ of the promoter activity of the SCBV839 sequence (Figure 3). The SCBV282 enhancer fragment contains 189 bp of ORF III coding sequence. A similar situation is found in Arabidopsis where regulatory elements for the promoter of ZWICHEL $(Z W I)$ gene are found in exon and intron sequences of the adjacent HYDROXYISOBUTYRL-CoA HYDROLASE 1 (CHY1) gene [49].

The enhancer sequences in the SCBV-IM promoter were able to increase the activity of the truncated ZmADH1 promoter (Figure 4), but these chimeric promoters were much weaker than the intact SCBV-IM promoter in the transient assays (Figure 3). This difference is so great it is unlikely to be the result of different cell preparations and may be the result of the SCBV-IM upstream activating sequences interacting differently with the heterologous core ZmADH1 promoter and the native SCBV-IM promoter. Similar results were seen when the CaMV $35 \mathrm{~S}$ enhancer was placed upstream of the CaMV 19S core promoter [38].

Deletion analysis of the SCBV-IM promoter showed that removing sequences from -770 to -507 caused a $30 \%$ decline in promoter activity, while removing sequences from -770 to -264 caused a $90 \%$ decline in activity (Figure 3). It was, therefore, somewhat surprising to observe that the chimeric promoter SCBV537:: ZmADH1 (containing SCBV-IM sequences -689 to -153 ) had less activity than the chimeric promoter SCBV282:: ZmADH1 (containing SCBV-IM sequences -434 to -153) since the longer fragment in the promoter deletion analysis had the most activity. Surprising results are often obtained when portions of promoters are added or deleted and even small portions of promoters can have dramatic effects. For example, Dey and Matti [15] showed that removing $50 \mathrm{bp}$ of the MMV promoter increased 


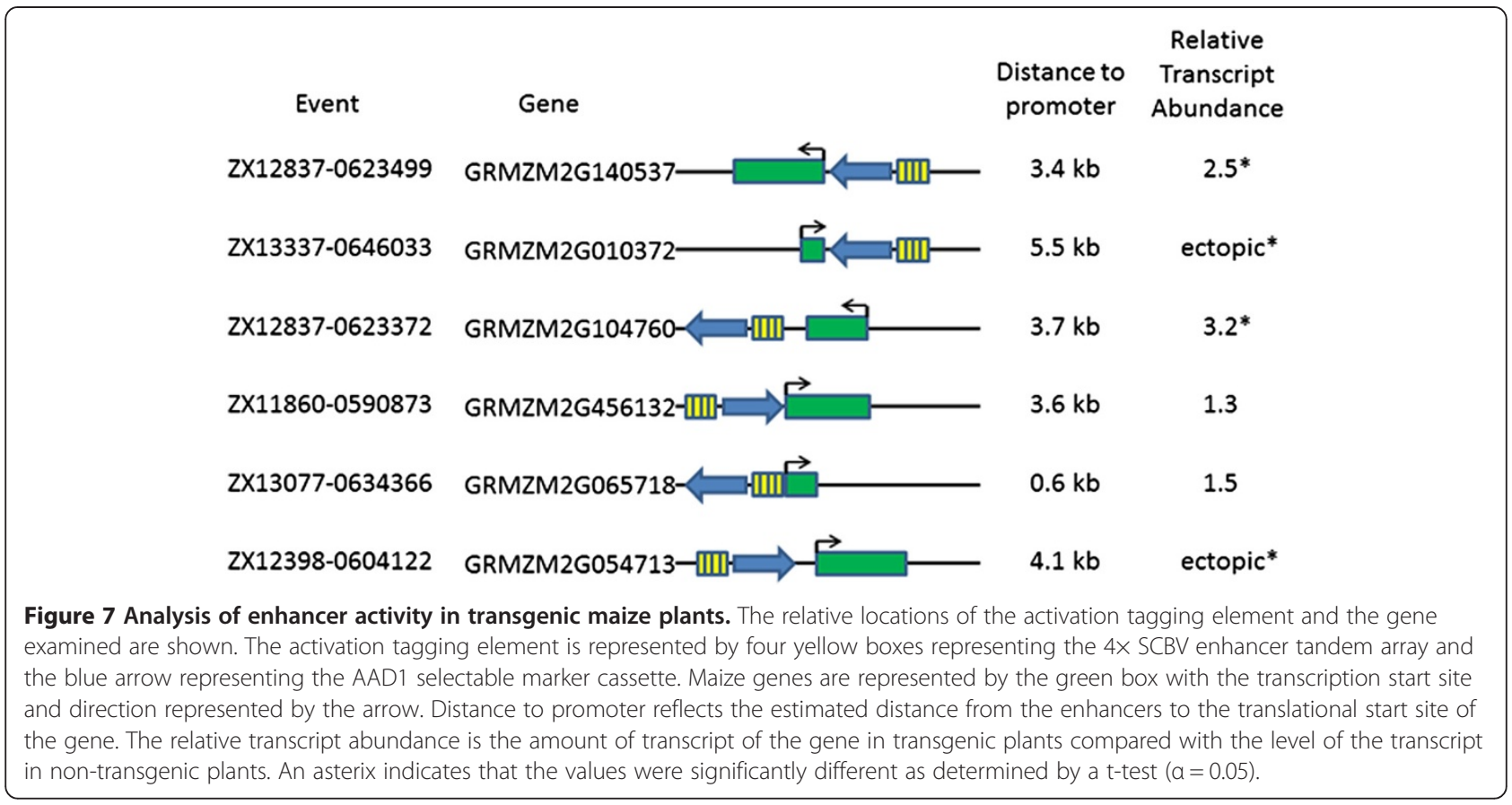

activity 10 fold and Simon et al. [50] showed that deleting $54 \mathrm{bp}$ of the Inner No Outer promoter of Arabidopsis could reverse a silenced promoter.

Multiple copies of the SCBV-IM enhancer cause an increase in activity of the chimeric promoters in transient assays (Figure 5). This is consistent with what has been observed with the CaMV 35S and FMV ehancers [8,37-39] and may be due to multiple copies of the enhancer being more efficent in recruiting transcription factors to the promoter.

The SCBV282 fragment is capable of acting as a transcriptional enhancer when present in the maize genome in a $4 \mathrm{x}$ tandem array. In events containing the 4x SCBV-IM enhancer upstream and downstream of genes, and in either orientation with respect to these genes, increased transcript accumulation was observed (Figure 7). Furthermore, the element appeared to cause accumulation of transcripts that are not present, or present in very low levels, in non-transgenic lines. This demonstrates that the SCBV-IM enhancer may be used for activation tagging in maize. The SCBV-IM enhancers increased expression of 2 out of 8 genes that showed non-detectable expression in non-transgenic control plants. This is similar some studies that have reported ectopic expression of genes when the CaMV $35 \mathrm{~S}$ enhancers integrate nearby $[51,52]$.

\section{Conclusions}

In this work, we demonstrate that the SCBV-IM promoter is comparable in strength to the ZmUBI1 promoter in transgenic young maize leaves and roots and we identify sequences from the SCBV-IM promoter that can function as a transcriptional enhancer in maize plants. We used transient assays to identify promoter sequences that are responsible for most of the promoter activity and sequences of this promoter that enhance expression from a heterologous promoter. Finally, we generated stable transgenic plants containing $4 \mathrm{x}$ tandem arrays of the SCBV-IM enhancer and demonstrated that transcripts of genes near the insertion site are more abundant than in non-transgenic control plants.

Activation tagging by randomly inserting transcriptional enhancers in the genome is a powerful tool for identifying gene function. The CaMV 35S enhancer has been used to develop activation tagging systems for Arabidopsis, rice and barley. Using these activation tagging systems, researchers have identified a number of genes with novel functions [28,53-57]. To date, no activation tagging system has been developed for maize. As a first step in developing an activation tagging system for maize, we have identified a transcriptional enhancer from SCBV-IM and have shown it to be able to activate transcription from a truncated $\mathrm{ZmADH} 1$ promoter in transient assays and from endogenous promoters in transformed maize plants.

\section{Methods \\ 5' RACE}

Leaf tissue was collected from seedlings of transgenic event 625-1 containing the SCBV-IM::AAD1 construct. Total RNA was prepared using NucleoSpin RNA Plant kit (Macherey-Nagel, Ref. 740949). 5' RACE was performed with AAD1 gene specific primer 
(GACTTGGTCTTTCTTCCACCTCACA) and SMARTer RACE 5'/3' kit (Clontech Labratories, CA. Cat\# 634858) following the manufacture's recommended methods. Sequeneces generated from the $5^{\prime}$ RACE were then aligned to the reference sequences of SCBV-IM promoter and $\mathrm{AAD} 1$ gene to determine the transcription start site.

\section{Plasmid construction}

The 839 bp SCBV-IM promoter sequence was synthesized by DNA2.0, Inc. The sequence is shown in Figure 2 (from GenBank accession AJ277091).

Two plant transformation vectors were constructed in the superbinary precursor plasmid pSB11. One of these contained the SCBV-IM promoter, aryloxyalkanoate dioxigenase herbicide resistance gene (AAD1) [40] and the maize Per5 3' UTR, while the other contained the maize ubiquitin promoter [26], AAD1 and the maize Per5 3' UTR. Between the T-DNA borders, these constructs also contained a ZmUBI promoter fused to the Phi Yellow Fluorescent Protein (PhiYFP) gene (Evrogen JSC, Moscow, Russia). These constructs were introduced into Agrobacterium tumefaciens strain LBA4404(pSB1) [58,59] to produce pDAB108625 and pDAB102110, respectively.

Fragments derived from the SCBV-IM promoter containing sequences $-770 \mathrm{bp}-+69$ bp (plasmid pSCBV839), -507 - +69 bp (plasmid pSCBV576), and $-264-+69$ bp (plasmid pSCBV333) of the SCBV-IM promoter were generated by PCR using the primers listed in Table 1. Fragments from the SCBV-IM promoter were cloned upstream of coding sequences for a firefly luciferase (LUC) reporter protein [60] (pEPP1020). The nopaline synthase (Nos) 3' UTR region (bases 1847 to 2103 of GenBank Accession No. V00087.1) was cloned downstream of the LUC reporter gene to serve as a 3' UTR.

Putative SCBV-IM enhancer sequences ( -434 to -153 , SCBV282 and -689 to -153 , SCBV537) were PCR amplified from the SCBV-IM promoter region. Chimeric promoters were made by fusing enhancer fragments from the SCBV-IM promoter and a truncated promoter fragment from the maize alcohol dehydrogenase $1(\mathrm{ZmADH} 1)$ gene

Table 1 PCR primers used to amplify portions of the SCBV promoter

\begin{tabular}{lll}
\hline Plasmid & Primer & Sequence \\
\hline pSCBV839 & Forward & TCCCCGCGGAAGCTAATGGATGGGGAAAACA \\
& Reverse & ACGCGTCGACTGCGGAAAGGGTAATTCTATTATTCAA \\
pSCBV576 & Forward & TCCCCGCGGGGTGAAAACTTCGACAAGAAAGCA \\
& Reverse & ACGCGTCGACTGCGGAAAGGTGTAATTCTATTATTCAA \\
pSCBV333 & Forward & TCCCCGCGGCCAGTGGAGGAGATCGTAAGCAATGA \\
& Reverse & ACGCGTCGACTGCGGAAGGTGTAATTCTATTATTCAA \\
\hline
\end{tabular}

corresponding to positions from -100 to +106 relative to the transcription start site [41]. The ZmADH1 promoter fragment was PCR amplified using genomic DNA from B73 using CGGGATCCGTATACCCACAGGCG GCCAAACCGC and CATGCCATGGTGCCCCCCTC CGCAAATCTT as the forward and reverse primers, respectively. The amplified PCR products were cloned upstream of the truncated $\mathrm{ZmADH} 1$ promoter fused to the luciferase gene. The promoter fragment was confirmed by sequencing. Two differences from the B73 reference sequence were observed; an " $A$ " instead of a " $G$ " at +44 bp and addition of " $\mathrm{T}$ " at residue $+67 \mathrm{bp}$.

The $1 \mathrm{x}, 2 \mathrm{x}$ and $4 \mathrm{x}$ enhancer fragments of SCBV282 fragment were cloned in the BamHI and BstZ17I sites of pEPP1024, a plasmid containing the truncated ZmADH1 promoter fused to the LUC gene, for transient testing of the transcriptional enhancing activities. The 4x SCBV enhancer array was cloned into pSB11-derived plasmid pDAB3878 which also contains the rice actin1 gene promoter [61] driving the AAD1 selectable marker [40]. Superbinary constructs were then constructed by in vivo recombination of $\mathrm{pSB} 1$ plasmid and the newly constructed pSB11 derivative plasmid in recombinant Agrobacterium tumefacians strain LBA4404/pSB1 to form superbinary construct pEPS1027.

\section{Plant transformation}

Constructs were introduced into the maize inbred line B104 using Agrobacterium-mediated transformation based on the superbinary method of Ishida et al. [62]. Maize plants (inbred B104) were grown in a greenhouse on a 16:8 hour Light:Dark photoperiod and hand pollinated using pollen from sibling plants. Immature embryos were isolated at 10 to 13 days after pollination when the embryos were 1.4 to $2.0 \mathrm{~mm}$ in size.

A suspension of Agrobacterium cells containing the superbinary vector pEPS1027 was prepared by transferring 1 or 2 loops of bacteria grown to solid medium containing $50 \mathrm{mg} / \mathrm{L}$ Spectinomycin, $10 \mathrm{mg} / \mathrm{L}$ Rifampicin, and $50 \mathrm{mg} / \mathrm{L}$ Streptomycin at $28^{\circ}$ for 3 days and then a loop of this culture was used to innoculate $5 \mathrm{~mL}$ of liquid infection medium (MS salts, ISU Modified MS Vitamin stock (1000x, $2 \mathrm{~g} / \mathrm{L}$ glycine, $0.5 \mathrm{~g} / \mathrm{L}$ each of thiamine $\mathrm{HCl}$ and pyridoxine $\mathrm{HCl}, 0.05 \mathrm{~g} / \mathrm{L}$ nicotinic acid, $3.3 \mathrm{mg} / \mathrm{L}$ Dicamba, $68.4 \mathrm{gm} / \mathrm{L}$ sucrose, $36 \mathrm{gm} / \mathrm{L}$ glucose, $700 \mathrm{mg} / \mathrm{L}$ L-proline, $\mathrm{pH}$ 5.2) containing $100 \mu \mathrm{M}$ acetosyringone for 4 days at $25^{\circ} \mathrm{C}$. This infection suspension was gently pipetted up and down using a sterile $5 \mathrm{~mL}$ pipette until a uniform suspension was achieved, and the concentration was adjusted to an optical density of 0.3 to 0.5 at $600 \mathrm{~nm}$.

Prior to embryo excision and transformation, maize ears were surface sterilized. Immature embryos were then isolated and placed in $2 \mathrm{~mL}$ of infection medium. The medium was removed and replaced twice with 1 to 
$2 \mathrm{~mL}$ of fresh infection medium, which was then removed and replaced with $1.5 \mathrm{~mL}$ of the infection suspension and incubated for 5 minutes at room temperature. Then embryos were then transferred to co-cultivation medium and inubated for 3-4 day at $25^{\circ} \mathrm{C}$ in the dark. Co-cultivation medium contained MS salts, ISU Modified MS Vitamins, $3.3 \mathrm{mg} / \mathrm{L}$ Dicamba, $30 \mathrm{gm} / \mathrm{L}$ sucrose, $700 \mathrm{mg} / \mathrm{L}$ L-proline, $100 \mathrm{mg} / \mathrm{L}$ myo-inositol, $100 \mathrm{mg} / \mathrm{L}$ Casein Enzymatic Hydrolysate, 15 mg/L AgNO3, $100 \mu \mathrm{M}$ acetosyringone, and 2.3 to $3 \mathrm{gm} / \mathrm{L}$ Gelzan ${ }^{\mathrm{mt}}$ (Sigma-Aldrich, St. Louis, MO), at pH 5.8.

After co-cultivation, the embryos were transferred to a MS-based resting medium containing MS salts, ISU Modified MS Vitamins, $3.3 \mathrm{mg} / \mathrm{L}$ Dicamba, $30 \mathrm{gm} / \mathrm{L}$ sucrose, $700 \mathrm{mg} / \mathrm{L}$ L-proline, $100 \mathrm{mg} / \mathrm{L}$ myo-inositol, $100 \mathrm{mg} / \mathrm{L}$ Casein Enzymatic Hydrolysate, $15 \mathrm{mg} / \mathrm{L}$ $\mathrm{AgNO}_{3}, 0.5 \mathrm{gm} / \mathrm{L}$ MES (2-(N-morpholino)ethanesulfonic acid monohydrate; Fischer Scientific, Waltham, MA), $250 \mathrm{mg} / \mathrm{L}$ Carbenicillin, and $2.3 \mathrm{gm} / \mathrm{L} \mathrm{Gelzan}^{\mathrm{Tx}}$, at $\mathrm{pH} 5.8$. Incubation continued for 7 days at $28^{\circ} \mathrm{C}$ in the dark. Following the 7 day resting period, the embryos were transferred to selection medium. MS-based resting medium (above) was used supplemented with Haloxyfop. The embryos were first transferred to selection medium containing $100 \mathrm{nM}$ Haloxyfop and incubated at $28^{\circ} \mathrm{C}$ for 1 to 2 weeks, and then transferred to selection medium containing $500 \mathrm{nM}$ Haloxyfop and incubated for an additional 2 to 4 weeks in the light (approximately $50 \mu \mathrm{Em}^{-2} \mathrm{~s}^{-1}$ ). Transformed isolates were obtained in 5 to 8 weeks.

Following selection, cultures were transferred to an MS-based pre-regeneration medium containing MS salts, ISU Modified MS Vitamins, $45 \mathrm{gm} / \mathrm{L}$ sucrose, $350 \mathrm{mg} / \mathrm{L}$ L-proline, $100 \mathrm{mg} / \mathrm{L}$ myo-inositol, $50 \mathrm{mg} / \mathrm{L}$ Casein Enzymatic Hydrolysate, $1 \mathrm{mg} / \mathrm{L} \mathrm{AgNO}_{3}, 0.25 \mathrm{gm} / \mathrm{L}$ MES, $0.5 \mathrm{mg} / \mathrm{L}$ naphthaleneacetic acid, $2.5 \mathrm{mg} / \mathrm{L}$ abscisic acid, $1 \mathrm{mg} / \mathrm{L}$ 6-benzylaminopurine, $250 \mathrm{mg} / \mathrm{L}$ Carbenicillin, $2.5 \mathrm{gm} / \mathrm{L}$ Gelzan ${ }^{\mathrm{nx}}$, and $500 \mathrm{nM}$ Haloxyfop, at pH 5.8 and incubated for 7 days at $28^{\circ}$ under 24-hour white fluorescent light (approximately $50 \mu \mathrm{Em}^{-2} \mathrm{~s}^{-1}$ ).

For regeneration, the cultures were transferred to an MS-based primary regeneration medium containing MS salts, ISU Modified MS Vitamins, $60 \mathrm{gm} / \mathrm{L}$ sucrose, $100 \mathrm{mg} / \mathrm{L}$ myo-inositol, $125 \mathrm{mg} / \mathrm{L}$ Carbenicillin, $2.5 \mathrm{gm} / \mathrm{L}$ Gelzan $^{\text {tw }}$, and $500 \mathrm{nM}$ Haloxyfop, at pH 5.8 for 2 weeks at $28^{\circ}$ in 24-hour white fluorescent light (approximately $50 \mu \mathrm{Em}^{-2} \mathrm{~s}^{-1}$ ). Cultures were then transferred to an MS-based secondary regeneration medium composed of MS salts, ISU Modified MS Vitamins, $30 \mathrm{gm} / \mathrm{L}$ sucrose, $100 \mathrm{mg} / \mathrm{L}$ myo-inositol, $3 \mathrm{gm} / \mathrm{L} \mathrm{Gelzan}^{\text {tw }}$, at $\mathrm{pH}$ 5.8, with $500 \mathrm{nM}$ Haloxyfop and regeneration continued for 2 weeks at $28^{\circ} \mathrm{C}$ under either 16-hour or 24-hour white fluorescent light conditions (approximately $50 \mu \mathrm{Em}^{-2} \mathrm{~s}^{-1}$ ). When regenerated plants reached 3 to $5 \mathrm{~cm}$ in length, they were excised and transferred to secondary regeneration medium (as above, but without Haloxyfop) and incubated at $25^{\circ}$ under 16-hour white fluorescent light conditions (approximately $50 \mu \mathrm{Em}^{-2} \mathrm{~s}^{-1}$ ) to allow for further growth and development of the shoot and roots.

Regenerated plants were transplanted into Metro-Mix ${ }^{\circ}$ 360 soilless growing medium (Sun Gro Horticulture) and placed a growth room. Plants were then transplanted into Sunshine Custom Blend 160 soil mixture and grown to flowering in the greenhouse. Controlled pollinations for seed production were conducted. In all cases, primary transformants were crossed with non-transformed B104.

\section{Transcript accumulation in transgenic plants}

Transgenic plants were identified by a quantitative PCR assay of the AAD1 gene. Approximately $30 \mathrm{mg}$ of T1 tissue was harvested from each of the tissues. Tissue samples were maintained on ice until placed at $4^{\circ} \mathrm{C}$ for storage until processing for DNA extraction. DNA was purified using the BioSprint DNA 96 plant kit following the manufacturer's instructions (Qiagen cat. No. 941558). Samples were normalized to $5 \mathrm{ng} / \mu \mathrm{L}$ for qPCR template. A Picogreen assay (Invitrogen, cat No. P11496) was performed to quantify DNA.

For transcript accumulation assays, samples were collected from leaves, roots and tassels at different times during development. For leaves, samples were collected at the V3 growth stage (14 days after planting) from the 3rd fully expanded leaf, at the V8 growth stage (41 days after planting) from the 8th fully expanded leaf and at the R1 growth stage (71 days after planting) from the leaf just below the ear. Samples from the root were collected at the V3 (14 days after planting) and V10 (51 days after planting) growth stages; one $\mathrm{cm}$ samples were collected from the tip of a root. Tassels were collected at the R1 growth stage by sampling an entire branch of the tassel. First strand cDNA was synthesized following manufacturer's instructions using the High Capacity cDNA synthesis kit (Invitrogen, cat No. 4368813) in a $10 \mu \mathrm{L}$ reaction containing $5 \mu \mathrm{L}$ of total RNA. Following synthesis, cDNA was diluted 1:3 with nuclease free water. Quantitative PCR assays were set up using the Eppendorf epMotion5075 liquid handler. Each sample was assayed in triplicate for target gene (AAD1) and a reference gene TIP (GRMZM2G095185) for leaf and tassel tissues or MAZ95 (GRMZM2G053299) for root tissues. Each well contained $4 \mu \mathrm{L}$ of assay mix (Roche Universal Probe Library (UPL)) and $1 \mu \mathrm{L}$ of cDNA was added. Reference assay mix consisted of forward (AGCCAAGCCAGTGGTACTTC) and reverse (TCGCAGACAAAGTAGCAAATGT) primer at a final concentration of $0.25 \mu \mathrm{M}$ and UPL probe at a final concentration of $0.1 \mu \mathrm{M}$ with $1 \mathrm{x}$ Light Cycler $480^{\circ}$ Probes Master mix. AAD1 assay mix consisted of forward (AACCATGCAAGCCACCAT) and reverse (GGTAGAG 
GGAACCGAACACA) primer at a final concentration of $0.375 \mu \mathrm{M}$ and UPL probe \#53 at a final concentration of $0.1 \mu \mathrm{M}$ with $1 \mathrm{x}$ Light Cycler $480^{\circ}$ Probes Master mix.

Detection was 6FAM channel in both assays. PCR cycling conditions were initially activated at $95^{\circ} \mathrm{C}$ for 10 minutes followed by 43 cycles of denaturation at $95^{\circ} \mathrm{C}$ for 10 seconds, annealing and extension at $60^{\circ} \mathrm{C}$ for 20 seconds and data acquisition for 1 second at $72^{\circ} \mathrm{C}$. Assay plates were run on the Roche LC480II and analysis performed by relative quantification.

\section{Transient assays in maize suspension cultures}

Maize Hi-II suspension culture cells [63] were transfected by particle bombardment with plasmid DNA constructs harboring promoter or enhancer elements driving the LUC gene and a control plasmid DNA construct containing a ZmUBI1::GUS gene for normalization of transfection.

Bulk preparations of plasmid DNAs were prepared using QiAfilter $^{\text {rm }}$ Plasmid Maxi Kits (Qiagen, Germantown, Maryland) and the quantity and quality were analyzed using standard molecular methods. The Hi-II cells were grown by shaking at $125 \mathrm{rpm}$ in $\mathrm{H} 9 \mathrm{CP}+$ medium $(\mathrm{H} 9 \mathrm{CP}$ medium consists of MS salts $4.3 \mathrm{gm} / \mathrm{L}$, sucrose $3 \%$, Casamino acids $200 \mathrm{mg} / \mathrm{L}$, myo-inositol $100 \mathrm{mg} / \mathrm{L}$, 2,4-D $2 \mathrm{mg} / \mathrm{L}$, NAA $2 \mathrm{mg} / \mathrm{L}, 1000 \mathrm{X}$ MS vitamins $1 \mathrm{~mL} / \mathrm{L}$, L-proline $700 \mathrm{mg} / \mathrm{L}$, and coconut water (Sigma Aldrich, St. Louis, MO) $62.5 \mathrm{~mL} / \mathrm{L}, \mathrm{pH}$ 6.0) at $28^{\circ} \mathrm{C}$ in the dark. Prior to bombardment, the 2-day old $\mathrm{Hi}-\mathrm{II}$ cultures were transferred to G-N6 medium (CHU N6 medium $3.98 \mathrm{~g} / \mathrm{L}, \mathrm{CHU}$ N6 vitamins $1 \mathrm{~mL} / \mathrm{L}$ (both $\mathrm{CHU}$ components were from PhytoTechnology Laboratories $^{\circledR}$, Lenexa, KS), Myo-inositol $100 \mathrm{mg} / \mathrm{L}$, 2,4-D $2 \mathrm{mg} / \mathrm{L}$ and sucrose 3\%, $\mathrm{pH}$ 6.0) and allowed to grow for 24 hours. On the day of bombardment, $2.5 \mathrm{~g}$ of G-N6 grown cells were transferred to sterile Whatman No. 1 filter disks (55 mm) placed on G-N6 medium containing $0.5 \mathrm{M} \mathrm{D}$-sorbitol and $0.5 \mathrm{M}$ D-mannitol and incubated for 4 hours. The osmotically-adjusted cells were used for bombardment.

Gold particles $(1 \mu \mathrm{m}$ diameter, BioRad, Hercules, CA) were washed with $70 \%$ ethanol for 10 minutes, then three times with sterile water. The particles were dispensed in $50 \%$ glycerol at a concentration of $120 \mathrm{mg} / \mathrm{mL}$. For a typical experiment, $150 \mu \mathrm{L}(18 \mathrm{mg})$ of gold particles, approximately $5 \mu \mathrm{g}$ of plasmid DNA, $150 \mu \mathrm{L}$ of $2.5 \mathrm{M}$ $\mathrm{CaCl}_{2}$ and $30 \mu \mathrm{L} 0.2 \mathrm{M}$ spermidine were combined. The reaction (total volume $375 \mu \mathrm{L}$ ) was incubated at room temperature for 10 minutes with occasional gentle vortexing. The DNA coated-gold particles were briefly centrifuged, washed with $420 \mu \mathrm{L}$ of $70 \%$ ethanol and then with $420 \mu \mathrm{L}$ of $100 \%$ ethanol. The final pellet was resuspended in $110 \mu \mathrm{L}$ of $100 \%$ ethanol and subjected to a brief sonication (three bursts of 3 seconds each, with 1 minute between bursts) with a Branson 1450 sonicator.
Table 2 Primers for insertion site mapping confirmation

\begin{tabular}{lll}
\hline Name & Locus & Sequence \\
\hline EA56 & GRMZM2G140537 & GATCTTTCTGGGGAGCGGTTC \\
EA200 & GRMZM2G010372 & ATAGAACGGAGGTGTCCAAAGTCTC \\
EA191 & GRMZM2G104760 & GCTCGTITITCCCCCATAGC \\
EA7 & GRMZM2G456132 & ACACCTTGCCGCACCGC \\
EA65 & GRMZM2G065718 & GGGTACTAGCTCAATCGTCGCTC \\
EA45 & GRMZM2G054713 & AGAGTTACTCATGCCGCAGCC \\
\hline
\end{tabular}

Aliquots of $12.2 \mu \mathrm{L}$ of the gold-particles coated with DNA were spread on each of nine macrocarriers (BioRad, Hercules, CA) and used in bombardment assays using a BioRad PDS1000/He system. The suspension culture cells were transfected at a target distance of $9 \mathrm{~cm}$ using 3510 psi disks and each plate was bombarded 3 times. Following bombardment, the cells were incubated in the dark at $28^{\circ}$, first for 12 hours on G-N6 containing D-sorbitol and D-mannitol medium, then on G-N6 plates for an additional 36 hours. Cells were collected from the plates, blotted to remove buffer and extracted with $300 \mu \mathrm{L}$ of $2 x$ CCLT LUC extraction buffer (Promega Corporation, Madison, WI). After centrifugation, about $600 \mu \mathrm{L}$ of protein extract was collected. Protein concentrations were estimated using the Bradford assay.

LUC enzymatic activity (expressed in Luciferase Units (LU)/mg protein) and GUS enzymatic activity (expressed in GUS activity units (GU)/ $\mu \mathrm{g}$ protein) were measured as previously described [64]. Relative activities of the test promoters in SCBV:LUC constructs were compared by normalizing LUC levels to GUS levels as the ratio of $\mathrm{LUC} / \mathrm{mg}$ protein:GUS/ $\mu$ g protein.

\section{Analysis of activation tagging events}

Flanking sequence from left border of the T-DNA insert for each line transformed with pEPS1027 was determined by

Table 3 PCR primer information for gene expression assays

\begin{tabular}{lll}
\hline Name & Sequence & Assay locus \\
\hline U1LT01_139_L & CTCGTGGAAGTCGGTGAAG & GRMZM2G140537 \\
U1LT01_139_R & ATCAGCTTGGACATCTCCTG & \\
U4LT01_443_L & GTTGCGTGGCGAGTAACAT & GRMZM2G010372 \\
U4LT01_443_R & GACGACATTCATGGCAGTTG & \\
U6RT01_272_L & CGAGTCGAAAGAAACGCTTG & GRMZM2G104760 \\
U6RT01_272_R & ATATATCGCAACTCACGCCC & \\
U7RT01_640_L & GGTTATTTCACCGCTCACGA & GRMZM2G456132 \\
U7RT01_640_R & TTTGTCATGTCCCATGACG & \\
U10RT01_150_L & CTTTCAAGTCGCCATCCTC & GRMZM2G065718 \\
U10RT01_150_R & GCCTCGTACGTCTTGAGCAC & \\
U14RT02_12_L & TCATTGAACGCTAGCTGCTG & GRMZM2G054713 \\
U14RT02_12_R & AAAGCTGGGGTTGGAATTG & \\
\hline
\end{tabular}


sequencing PCR products derived using a transgene border sequence identification method [45]. Mapping and identification of distances to nearest genes upstream and downstream of the insertion was performed by an automated flanking sequence analysis program [65]. The location of the insert was verified by $\mathrm{PCR}$ using left border flank primer, SHnstF (CTGTTCCTGACTATGCTGGCAAGT), as forward primer paired with a locus specific reverse primer as indicated in Table 2.

To determine whether transcripts of genes adjacent to the activation tagging element were more abundant in transgenic plants than non-transgenic plants, leaf samples were taken from V5 leaf tissues [44] and total RNA isolated as before. Transcript abundance was measured using quantitative reverse transcriptase PCR (RT-qPCR). First strand cDNA was prepared using the high capacity cDNA Reverse Transcription kit (Life Technologies \#4368814) in a $10 \mu \mathrm{L}$ reaction volume with $250-500$ ng total RNA. Reaction products were diluted 1:3 with water and assayed using the Absolute Blue qPCR SYBR Green kit (ThermoFisher \#AB-4166B). PCR reactions containing each primer at $200 \mathrm{nM}$ final concentration and $1 \mu \mathrm{L}$ of diluted template in a $7 \mu \mathrm{L}$ final volume were performed. Primers used in gene specific assays are shown in Table 3. The PCR program consisted of activation at $95^{\circ} \mathrm{C}$ for 15 minutes followed by cycling with sequential steps of denaturation at $95^{\circ} \mathrm{C}$ for 15 seconds, annealing at $58^{\circ} \mathrm{C}$ for 30 seconds and extension at $72^{\circ} \mathrm{C}$ for 15 seconds with the last step being used for data acquisition. A total of 40 cycles were used.

\section{Availability of supporting data}

The data sets supporting the results of this article are included within the article.

\section{Competing interests}

The authors declare that they have no competing interests.

\section{Authors' contributions}

DRW, ASR and JPD conceived of and supervised the work. VR, WMA, MT and JPD conceived of using the SCBV enhancer. VR, XLL, JPD, LSD, ZC, JC and DOG designed experiments and analyzed results. VR, XLL, ZC and JC conducted and supervised the experiments. JPD wrote the manuscript and all the authors read, corrected and approved the final manuscript.

\footnotetext{
Acknowledgements

We would like to acknowledge Deka Smith, Suyan Wang and Wendy Matsumura for their assistance in generating constructs, analyzing transgenic plants, Nikolaus Matheis, Fira Negru and Morioara Tomuta for transformation of maize and Tyler Spurgeon, Michael Paruch and Cheryl Maahs for growing, caring for and harvesting transgenic plants and Kelli Gibson and Kristina Woodall for RNA isolation and first-strand cDNA synthesis.
}

\section{Author details}

'Dow AgroSciences, 16160 SW Upper Boones Ferry Rd, Portland, OR 97224, USA. ${ }^{2}$ Dow AgroSciences, 9330 Zionsville Rd, Indianapolis, IN 46268, USA. ${ }^{3}$ Current address: GEVO, Inc., 345 Inverness Dr S C-310, Englewood, CO 80112, USA. ${ }^{4}$ Current address: Agrinos, Inc, 279 Cousteau Place, Davis, CA 95618, USA.
Received: 22 August 2014 Accepted: 27 November 2014

Published online: 19 December 2014

\section{References}

1. Blackwood EM, Kadonaga JT: Going the Distance: A Current View of Enhancer Action. Science 1998, 281(5373):60-63.

2. Struhl K: A Paradigm for Precision. Science 2001, 293(5532):1054-1055.

3. Wu K, Hu M, Martin T, Wang C, Li X-Q, Tian L, Brown D, Miki B: The cryptic enhancer elements of the tCUP promoter. Plant Mol Biol 2003, 51(3):351-362.

4. Wu K, Malik K, Tian L, Hu M, Martin T, Foster E, Brown D, Miki B: Enhancers and core promoter elements are essential for the activity of a cryptic gene activation sequence from tobacco, tCUP. Mol Gen Genomics 2001, 265(5):763-770.

5. Sandhu J, Webster C, Gray J: A/T-rich sequences act as quantitative enhancers of gene expression in transgenic tobacco and potato plants. Plant Mol Biol 1998, 37(5):885-896.

6. Benfey PN, Ren L, Chua NH: The CaMV 35 S enhancer contains at least two domains which can confer different developmental and tissue-specific expression patterns. EMBO J 1989, 8(8):2195-2202.

7. Odell JT, Nagy F, Chua $\mathrm{N}-\mathrm{H}$ : Identification of DNA sequences required for activity of the cauliflower mosaic virus 35 S promoter. Nature 1985 , 313(6005):810-812.

8. Maiti IB, Gowda S, Kiernan J, Ghosh SK, Shepherd RJ: Promoter/leader deletion analysis and plant expression vectors with the figwort mosaic virus (FMV) full length transcript (FLt) promoter containing single or double enhancer domains. Transgenic Res 1997, 6(2):143-156.

9. O'Grady K, Gurley WB: Site-directed mutagenesis of the enhancer region of the 780 gene promoter of T-DNA. Plant Mol Biol 1995, 29(1):99-108.

10. Bruce WB, Bandyopadhyay R, Gurley WB: An enhancer-like element present in the promoter of a T-DNA gene from the Ti plasmid of Agrobacterium tumefaciens. Proc Natl Acad Sci 1988, 85(12):4310-4314.

11. Ellis JG, Llewellyn DJ, Walker JC, Dennis ES, Peacock WJ: The ocs element: a 16 base pair palindrome essential for activity of the octopine synthase enhancer. EMBO J 1987, 6(11):3203-3208.

12. Chen G, Müller M, Potrykus I, Hohn T, Fütterer J: Rice tungro bacilliform virus: transcription and translation in protoplasts. Virology 1994, 204(1):91-100.

13. Fukuoka H, Ogawa T, Mitsuhara I, Iwai T, Isuzugawa K, Nishizawa Y, Gotoh Y, Nishizawa Y, Tagiri A, Ugaki M: Agrobacterium-mediated transformation of monocot and dicot plants using the NCR promoter derived from soybean chlorotic mottle virus. Plant Cell Rep 2000, 19(8):815-820.

14. Dey N, Maiti I: Structure and promoter/leader deletion analysis of mirabilis mosaic virus (MMV) full-length transcript promoter in transgenic plants. Plant Mol Biol 1999, 40(5):771-782.

15. Dey N, Maiti I: Promoter deletion and comparative expression analysis of the Mirabilis mosaic caulimovirus (MMV) sub-genomic transcript (Sgt) promtoer in transgenic plants. Transgenics 2003, 4:35-53.

16. Bhattacharyya S, Dey N, Maiti IB: Analysis of cis-sequence of subgenomic transcript promoter from the Figwort mosaic virus and comparison of promoter activity with the cauliflower mosaic virus promoters in monocot and dicot cells. Virus Res 2002, 90(1-2):47-62.

17. Sanger M, Daubert $S$, Goodman R: Characteristics of a strong promoter from figwort mosaic virus: comparison with the analogous 355 promoter from cauliflower mosaic virus and the regulated mannopine synthase promoter. Plant Mol Biol 1990, 14(3):433-443.

18. Maiti IB, Shepherd RJ: Isolation and Expression Analysis of Peanut Chlorotic Streak Caulimovirus (PCISV) Full-Length Transcript (FLt) Promoter in Transgenic Plants. Biochem Biophys Res Commun 1998, 244(2):440-444.

19. Schenk PM, Remans T, Sagi L, Elliott AR, Dietzgen RG, Swennen R, Ebert PR, Grof CP, Manners JM: Promoters for pregenomic RNA of banana streak badnavirus are active for transgene expression in monocot and dicot plants. Plant Mol Biol 2001, 47(3):399-412.

20. Stavolone L, Kononova M, Pauli S, Ragozzino A, de Haan P, Milligan S, Lawton K, Hohn T: Cestrum yellow leaf curling virus (CmYLCV) promoter: a new strong constitutive promoter for heterologous gene expression in a wide variety of crops. Plant Mol Biol 2003, 53(5):703-713.

21. Braithwaite KS, Geijskes RJ, Smith GR: A variable region of the Sugarcane Bacilliform Virus (SCBV) genome can be used to generate promoters for transgene expression in sugarcane. Plant Cell Rep 2004, 23(5):319-326. 
22. Tzafrir I, Torbert K, Lockhart BL, Somers D, Olszewski N: The sugarcane bacilliform badnavirus promoter is active in both monocots and dicots. Plant Mol Biol 1998, 38(3):347-356.

23. Cornejo M-J, Luth D, Blankenship K, Anderson O, Blechl A: Activity of a maize ubiquitin promoter in transgenic rice. Plant Mol Biol 1993, 23(3):567-581.

24. Gallo-Meagher M, Irvine J: Effects of tissue type and promoter strength on transient GUS expression in sugarcane following particle bombardment. Plant Cell Rep 1993, 12(12):666-670.

25. McElroy D, Blowers AD, Jenes B, Wu R: Construction of expression vectors based on the rice actin 1 (Act1) 5 ' region for use in monocot transformation. Mol Gen Genet MGG 1991, 231(1):150-160.

26. Christensen AH, Sharrock RA, Quail PH: Maize polyubiquitin genes: structure, thermal perturbation of expression and transcript splicing, and promoter activity following transfer to protoplasts by electroporation. Plant Mol Biol 1992, 18(4):675-689.

27. Jeong DH, An S, Kang HG, Moon S, Han JJ, Park S, Lee HS, An K, An G: T-DNA insertional mutagenesis for activation tagging in rice. Plant Physiol 2002, 130(4):1636-1644.

28. Wan S, Wu J, Zhang Z, Sun X, Lv Y, Gao C, Ning Y, Ma J, Guo Y, Zhang Q, Zheng $X$, Zhang $C$, Ma Z, Lu T.: Activation tagging, an efficient tool for functional analysis of the rice genome. Plant Mol Biol 2009, 69(1-2):69-80.

29. Jeong DH, An S, Park S, Kang HG, Park GG, Kim SR, Sim J, Kim YO, Kim MK, Kim SR, Kim J, Shin M, Jung M, An G: Generation of a flanking sequencetag database for activation-tagging lines in japonica rice. Plant J 2006, 45 (1):123-132

30. Qu S, Desai A, Wing R, Sundaresan V: A versatile transposon-based activation tag vector system for functional genomics in cereals and other monocot plants. Plant Physiol 2008, 146(1):189-199.

31. Medberry SL, Lockhart BEL, Olszewski NE: Properties of Commelina yellow mottle virus's complete DNA sequence, genomic discontinuities and transcript suggest that it is a pararetrovirus. Nucleic Acids Res 1990, 18(18):5505-5513.

32. Qu R, Bhattacharyya M, Laco GS, De Kochko A, Subba Rao B, Kaniewska MB, Scott Elmer J, Rochester DE, Smith CE, Beachy RN: Characterization of the genome of rice tungro bacilliform virus: Comparison with $<\mathrm{i}>$ Commelina</i > yellow mottle virus and caulimoviruses. Virology 1991, 185(1):354-364.

33. Bouhida M, Lockhart B, Olszewski NE: An analysis of the complete sequence of a sugarcane bacilliform virus genome infectious to banana and rice. J Gen Virol 1993, 74:15-22.

34. Medberry SL, Lockhart B, Olszewski NE: The Commelina yellow mottle virus promoter is a strong promoter in vascular and reproductive tissues. Plant Cell Online 1992, 4(2):185-192.

35. Yang IC, lommarini JP, Becker DK, Hafner GJ, Dale JL, Harding RM: A promoter derived from taro bacilliform badnavirus drives strong expression in transgenic banana and tobacco plants. Plant Cell Rep 2003, 21(12):1199-1206.

36. Schenk PM, Sagi L, Remans T, Dietzgen RG, Bernard MJ, Graham MW, Manners JM: A promoter from sugarcane bacilliform badnavirus drives transgene expression in banana and other monocot and dicot plants. Plant Mol Biol 1999, 39(6):1221-1230.

37. Kay R, Chan A, Daly M, McPherson J: Duplication of CaMV 35S Promoter Sequences Creates a Strong Enhancer for Plant Genes. Science (New York, NY) 1987, 236(4806):1299-1302.

38. OW DW, Jacobs JD, Howell SH: Functional regions of the cauliflower mosaic virus 35 S RNA promoter determined by use of the firefly luciferase gene as a reporter of promoter activity. Proc Natl Acad Sci 1987, 84(14):4870-4874

39. Fang RX, Nagy F, Sivasubramaniam S, Chua NH: Multiple cis regulatory elements for maximal expression of the cauliflower mosaic virus $35 \mathrm{~S}$ promoter in transgenic plants. Plant Cell Online 1989, 1(1):141-150.

40. Wright TR, Shan G, Walsh TA, Lira JM, Cui C, Song P, Zhuang M, Arnold NL, Lin G, Yau K, Russel SM, Cicchillo RM, Peterson MA, Simpson MD, Zhou N, Ponsamuel J, Zhang Z: Robust crop resistance to broadleaf and grass herbicides provided by aryloxyalkanoate dioxygenase transgenes. Proc Natl Acad Sci U S A 2010, 107(47):20240-20245.

41. Ellis J, Llewellyn D, Dennis E, Peacock W: Maize Adh-1 promoter sequences control anaerobic regulation: addition of upstream promoter elements from constitutive genes is necessary for expression in tobacco. EMBO J 1987, 6(1):11.
42. Leon P, Planckaert F, Walbot V: Transient gene expression in protoplasts of Phaseolus vulgaris isolated from a cell suspension culture. Plant Physiol 1991, 95(3):968-972.

43. Cowen NM, Armstrong K, Smith KA: Use of regulatory sequences in transgenic plants. In US Patent 7, Volume 179; 2007:902.

44. Sekhon RS, Lin H, Childs KL, Hansey CN, Buell CR, de Leon N, Kaeppler SM: Genome-wide atlas of transcription during maize development. Plant J 2011, 66(4):553-563.

45. Cao Z, Novak S, Sastry-Dent L, Zhou N: High through-put analysis of transgene borders. In vol. WO2013078318A1 World Intellectual Property Organization WO2013078318A1; 2013

46. Ichikawa T, Nakazawa M, Kawashima M, Muto S, Gohda K, Suzuki K, Ishikawa A, Kobayashi H, Yoshizumi T, Tsumoto Y: Sequence database of 1172 T-DNA insertion sites in Arabidopsis activation-tagging lines that showed phenotypes in T1 generation. Plant J 2003, 36(3):421-429.

47. Levine $M$, Tjian R: Transcription regulation and animal diversity. Nature 2003, 424(6945):147-151.

48. Banerji J, Rusconi S, Schaffner W: Expression of a $\beta$-globin gene is enhanced by remote SV40 DNA sequences. Cell 1981, 27(2):299-308,

49. Reddy VS, Reddy A: Developmental and cell-specific expression of ZWICHEL is regulated by the intron and exon sequences of its upstream protein-coding gene. Plant Mol Biol 2004, 54(2):273-293.

50. Simon MK, Williams LA, Brady-Passerini K, Brown RH, Gasser CS: Positiveand negative-acting regulatory elements contribute to the tissue-specific expression of INNER NO OUTER, a YABBY-type transcription factor gene in Arabidopsis. BMC Plant Biol 2012, 12(1):214

51. Yoo SY, Bomblies K, Yoo SK, Yang JW, Choi MS, Lee JS, Weigel D, Ahn JH: The $35 \mathrm{~S}$ promoter used in a selectable marker gene of a plant transformation vector affects the expression of the transgene. Planta 2005, 221(4):523-530.

52. Xu Y-Y, Wang X-M, Li J, Li J-H, Wu J-S, Walker JC, Xu Z-H, Chong K: Activation of the WUS gene induces ectopic initiation of floral meristems on mature stem surface in Arabidopsis thaliana. Plant Mol Biol 2005, 57(6):773-784.

53. van der Fits $L$, Memelink J: ORCA3, a jasmonate-responsive transcriptional regulator of plant primary and secondary metabolism. Science 2000, 289(5477):295-297.

54. Busov VB, Meilan R, Pearce DW, Ma C, Rood SB, Strauss SH: Activation tagging of a dominant gibberellin catabolism gene (GA 2-oxidase) from poplar that regulates tree stature. Plant Physio/ 2003, 132(3):1283-1291.

55. Mathews H, Clendennen SK, Caldwell CG, Liu XL, Connors K, Matheis N, Schuster DK, Menasco DJ, Wagoner W, Lightner J, Wagner DR: Activation tagging in tomato identifies a transcriptional regulator of anthocyanin biosynthesis, modification, and transport. Plant Cell 2003, 15(8):1689-1703.

56. Kakimoto T: CKI1, a histidine kinase homolog implicated in cytokinin signal transduction. Science 1996, 274(5289):982-985.

57. Ayliffe MA, Pallotta M, Langridge P, Pryor AJ: A barley activation tagging system. Plant Mol Biol 2007, 64(3):329-347.

58. Komari T, Takakura Y, Ueki J, Kato N, Ishida Y, Hiei Y: Binary vectors and super-binary vectors. Methods Mol Biol 2006, 343:15-41.

59. Komori T, Imayama T, Kato N, Ishida Y, Ueki J, Komari T: Current status of binary vectors and superbinary vectors. Plant Physiol 2007, 145(4):1155-1160.

60. DeLuca M, McElroy W: Purification and properties of firefly luciferase. Methods Enzymol 1978, 57:3-15.

61. McElroy D, Zhang W, Cao J, Wu R: Isolation of an efficient actin promoter for use in rice transformation. Plant Cell 1990, 2(2):163-171.

62. Ishida $Y$, Hiei $Y$, Komari T: Agrobacterium-mediated transformation of maize. Nat Protoc 2007, 2(7):1614-1621.

63. Armstrong C, Green C, Philips R: Development and availability of germplasm with high Type II culture formation response. Maize Genetics Coop Newsletter 1991, 65:92-93

64. Rosenkrans L, Vasil V, Vasil I, McCarty D: Functional analysis of a plant transcription factor using transient expression in maize protoplasts. In Edited by Maliga P, Klessig DF, Cashmore AR, Gruissem W; 1995:19-35.

65. Sastry-Dent L, Sriram S, Elango N, Cao Z, Muthuranman KN: Data analysis of dna sequences. In vol. WO2013119770A1 World Intellectual Property Organization WO2013119770A1; 2013. 